Review began 09/01/2021 Review ended 09/07/2021 Published 09/21/2021

๑) Copyright 2021

Porche et al. This is an open access article distributed under the terms of the Creative Commons Attribution License CC-BY 4.0., which permits unrestricted use, distribution, and reproduction in any medium, provided the original author and source are credited.

\section{Preoperative Radiographic Prediction Tool for Early Postoperative Segmental and Lumbar Lordosis Alignment After Transforaminal Lumbar Interbody Fusion}

\author{
Ken Porche ${ }^{1}$, Alexander Dru ${ }^{1}$, Rachel Moor ${ }^{1}$, Paul Kubilis ${ }^{1}$, Sasha Vaziri ${ }^{1}$, Daniel J. Hoh ${ }^{2}$ \\ 1. Neurosurgery, University of Florida, Gainesville, USA 2. Neurosurgery, University of Florida College of Medicine, \\ Gainesville, USA
}

Corresponding author: Ken Porche, kporche1012@gmail.com

\section{Abstract \\ Objective}

Transforaminal lumbar interbody fusion (TLIF) is a common approach and results in varying degrees of lordosis correction. The purpose of this study is to determine preoperative radiographic spinopelvic parameters that predict change in postoperative segmental and lumbar lordosis after TLIF.

\section{Materials \& Methods}

This study is a single surgeon retrospective review of one-level and two-level TLIFs from L3-S1. All patients underwent bilateral facetectomies, $10 \mathrm{~mm}$ TLIF cage (non-lordotic) insertions, and bilateral pedicle screwrod construct placements. Pre- and post-operative X-rays were assessed for preoperative segmental lordosis (SL), lumbar lordosis (LL), and pelvic incidence (PI). Univariate and multi-predictor linear regression analyses were performed to determine the relationships between preoperative radiographic findings and change in early postoperative segmental and lumbar lordosis.

\section{Results}

Ninety-seven patients contributing 128 intervertebral segments were examined. The mean change in SL after TLIF was 7.3 (range: $0.10-28.9^{\circ}$, SD $6.39^{\circ}$ ). The mean change in LL after TLIF was $5.5^{\circ}$ (range: -14.8 $39.2^{\circ}$, standard deviation (SD) $7.16^{\circ}$ ). Greater preoperative LL predicted less postoperative LL correction, while greater preoperative PI predicted more postoperative SL and LL correction. Greater anterior disk height was noted to be associated with a decreased change in SL ( $\Delta \mathrm{SL})$. An annular tear on preoperative magnetic resonance imaging (MRI) predicted a $2.7^{\circ}$ decrease in $\Delta$ SL. A Schmorl's node on preoperative MRI predicted a $4.0^{\circ}$ decrease in change in $\mathrm{LL}(\Delta \mathrm{LL})$.

\section{Conclusions}

A greater preoperative lordosis and a lower spinopelvic mismatch lessen the potential for an increase in the postoperative SL and LL after a TLIF, which is likely due to a 'ceiling' effect of an otherwise optimized spinal alignment. A greater anterior disk height and the presence of an annular tear are associated with decreased $\Delta \mathrm{SL}$.

Categories: Radiology, Neurosurgery

Keywords: transforaminal lumbar interbody fusion, radiographic outcomes, posterior lumbar interbody fusion, lumbar spine fusion, lordosis

\section{Introduction}

Transforaminal lumbar interbody fusion (TLIF) is a widely used, safe, and efficacious approach for surgical management of lumbar degenerative disease and spinal deformity [1-4]. TLIF is commonly performed to restore disk height, achieve circumferential neural decompression, relieve neuroforaminal stenosis, and augment posterior construct rigidity [5, 6]. A unique potential advantage of lumbar interbody fusion is restoration of segmental lordosis (SL) and optimization of sagittal alignment [7-11]. When compared to stand-alone posterior fusion, the reduction of pelvic incidence (PI)-lumbar lordosis (LL) mismatch achieved with TLIF results in decreased adjacent segment disease, diminished need for revision surgery, and improved postoperative patient satisfaction $[12,13]$.

Sagittal imbalance is the primary predictor of disability in adult spinal deformity, and restoration of sagittal alignment with spinopelvic harmony (or matched PI and LL) is known to lead to the best long-term outcomes in patients who undergo surgical correction [14, 15, 16, 17]. Previous studies have cited varying degrees of lordosis correction following TLIFs. These widely range from 2.1 - 27.3 degrees, depending on 
factors such as the use of lordotic cages, the number of levels instrumented, and whether the TLIF was performed in an open versus minimally invasive fashion [8, 9, 18-29]. Traditionally, radiographic factors, such as bridging osteophytes or the presence of intradiscal vacuum phenomenon, have been used to predict the capacity to restore SL [30]. Additional factors cited in the literature that may contribute to greater lordosis restoration include multilevel fusion, cage size, use of the cantilever TLIF technique, low preoperative SL, and high preoperative spinopelvic mismatch [18, 19, 24, 31, 32].

Currently, there are limited studies that use patient-specific imaging characteristics to predict SL correction after TLIF [33]. Therefore, the objective of this analysis is to demonstrate a patient-specific algorithm for the prediction of early postoperative degree of SL and LL correction after TLIF.

\section{Materials And Methods}

After obtaining approval from the University of Florida's internal review board (IRB202002814), we conducted a single surgeon retrospective review of all patients that underwent one- and two-level TLIFs from levels L3-S1, between 2010 and 2015. Data was de-identified and therefore, informed consent was not sought. Patients less than 18 years of age were excluded from this study. Each patient included in the study had preoperative 36-inch standing x-rays and post-operative lumbar x-rays. Additionally, 39\% had a preoperative lumbar computerized tomography (CT) scan and 95\% had a preoperative lumbar MRI. Each patient included in the study underwent a standard open TLIF technique (as previously described) involving a laminectomy with complete bilateral facetectomies, bilateral pedicle screw-rod construct placements, and placement of a 10mm non-lordotic cage (Concorde, Depuy Synthes, Raynham, MA, USA).

\section{Data acquisition}

Preoperative and immediate postoperative x-rays were assessed for spinopelvic parameters, including LL, SL and PI. LL was defined as the Cobb angle between the superior endplates of L1 and S1. SL was defined as the Cobb angle between the superior endplate above and the inferior endplate below the operative level. PI was defined as the angle between a line perpendicular to the sacral plate at its midpoint and a line connecting this point to the femoral head axis. The spinopelvic mismatch was calculated as PI-LL. Changes in LL and SL were calculated by determining the difference between pre- and postoperative Cobb angles of the lumbar spine and at the level(s) of operation, respectively. Immediate postoperative $\mathrm{x}$-rays were used to determine the change in the SL and LL to reflect the primary effect of the TLIF procedure on spinal alignment. Additional radiographic assessments of the intervertebral segment(s) at the operative level(s) were performed using preoperative MRI and CT scans, including the anterior disk height, annular tears, presence of a Schmorl's node, Modic type endplate change, bridging osteophytes, and vacuum disk. All preoperative disk characteristics and pre-/postoperative spinal measurements were performed and collected by two individuals (KP and $\mathrm{AD}$ ), with a calculated discordance of $2.3 \%$ when considering all values included in the study.

\section{Statistical Methods}

We used the mixed effect linear regression to fit single- and multi-predictor models of change in LL ( $\triangle \mathrm{LL})$ and SL $(\Delta \mathrm{SL})[34,35]$. Possible non-linearity of continuous predictors was evaluated using restricted cubic splines and co-linearity was evaluated using a variable clustering method and variance inflation factors (VIF) cutoff of 2 [34]. We then applied a backward elimination selection procedure to the remaining predictors [34]. We re-ran the backward elimination process on 100 bootstrap samples of the original dataset and tallied the frequency with which each predictor from our original candidate list was selected over the 100 final model fits. Our final best models consisted of predictors that were selected in $>50 \%$ of these model fits.

We used the adjusted R-square to assess the predictive performance of our best multi-predictor linear regression models and validated using Efron's "optimism" [34]. Residual analysis indicated normally distributed errors for both outcome models. Best model regression coefficients are presented along with $95 \%$ confidence limits and t statistic p-values for tests of whether the coefficients differed significantly from zero. We identified the region of the $\Delta \mathrm{LL}$ and $\Delta \mathrm{SL}$ response surfaces defined by PI and preoperative LL that differed significantly from $\triangle \mathrm{LL}=0$ or $\Delta \mathrm{SL}=0$, adjusting the confidence region using Scheffe's adjustment for multiple testing [34]. Statistical calculations were performed using SAS Version 9.4 (SAS Institute, Cary NC) and R Version 3.5.0 (R Foundation for Statistical Computing, Vienna, Austria).

\section{Results}

A total of 97 patients undergoing TLIFs at 128 levels were examined (Table 1). Sixty-six patients underwent single level, and 31 two-level TLIFs. The mean age was 62.5 years (standard deviation (SD) 11.63), and 44 $(47.3 \%)$ of the patients were male, with an average body mass index (BMI) of 30.24 (SD 6.14). The LL analysis consisted of 66 one-level patients with L3-L4, L4-L5, and L5-S1 disk involvements and 27 two-level patients. The SL analysis consisted of 66 disks from one-level patients and 54 disks from two-level patients. 


\section{Cureus}

\begin{tabular}{|c|c|}
\hline Variable & N (\%) \\
\hline All patients & 93 \\
\hline All disks & 120 \\
\hline 1-Level & $66(71.0)$ \\
\hline L3-L4 & $17(18.3)$ \\
\hline L4-L5 & $34(36.6)$ \\
\hline L5-S1 & $15(16.1)$ \\
\hline 2-Level & $27(29.0)$ \\
\hline L3-L5 & $7(7.5)$ \\
\hline L3-L4 \& L5-S1 & $1(1.1)$ \\
\hline L4-S1 & $19(20.4)$ \\
\hline Male & $44(47.3)$ \\
\hline Female & $49(52.7)$ \\
\hline Prior surgery & 39 (41.9) \\
\hline Bridging osteophytes & $10(10.8)$ \\
\hline Vacuum disks & $51(54.8)$ \\
\hline Annular tears & $28(31.1)^{*}$ \\
\hline Modic changes & $48(53.3)^{*}$ \\
\hline Schmorl's nodes & $19(21.4)^{*}$ \\
\hline
\end{tabular}

TABLE 1: Frequencies and percent occurrences of patient and disk space characteristics.

*Note: 1 missing for each of these variables due to missing magnetic resonance imaging.

\section{Preoperative intervertebral segment characteristics}

The average anterior disk height was $8.41 \mathrm{~mm}$ (range: $0.14-23.20$, SD 3.85). There were 32 patients with annular tears (26.02\%), 26 patients with a Schmorl's node (21.31\%), 63 patients with Modic type endplate changes (51.22\%), and 60 patients with intradiskal vacuum phenomena (46.88\%).

\section{Preoperative spinopelvic parameters}

The average preoperative PI was 56.96 (SD 14.12) (Table 2). The average preoperative LL was 48.79 (SD 11.47), and the average preoperative SL was 16.64 (SD 8.16). The mean preoperative PI-LL mismatch was 8.05 (SD 13.80). 


\section{Cureus}

\begin{tabular}{|lll|}
\hline Variable & N & Mean \pm SD \\
\hline Age & 93 & $62.25 \pm 11.53 \mathrm{yrs}$ \\
BMI & 93 & $30.02 \pm 6.12$ \\
Anterior disk height & 120 & $8.42 \pm 3.93 \mathrm{~mm}$ \\
Preop SL & 120 & $16.64 \pm 8.16^{\circ}$ \\
PI & 93 & $56.96 \pm 14.12^{\circ}$ \\
Preop LL & 93 & $48.91 \pm 11.10^{\circ}$ \\
PI-LL & 93 & $8.05 \pm 13.80^{\circ}$ \\
Postop SL & 120 & $23.97 \pm 8.51^{\circ}$ \\
Postop LL & 93 & $54.40 \pm 10.86^{\circ}$ \\
$\Delta S L$ & 120 & $7.33 \pm 6.39^{\circ}$ \\
\hline LL & 93 & $5.50 \pm 7.16^{\circ}$ \\
\hline
\end{tabular}

\section{TABLE 2: Means and standard deviations (SD) of patient and disk space characteristics.}

$\mathrm{N}$ = number, $\mathrm{SD}=$ standard deviation; $\mathrm{BMI}=$ body mass index; $\mathrm{SL}$ = segmental lordosis; $\mathrm{PI}$ = pelvic incidence; $\mathrm{LL}=$ lumbar lordosis; change in $\mathrm{SL}(\Delta \mathrm{SL}$ ); change in $\mathrm{LL}(\Delta \mathrm{LL})$.

\section{Immediate postoperative change in segmental and lumbar lordoses}

All TLIF levels demonstrated an increase in SL $\left(\Delta \mathrm{SL}\right.$ ), with a mean improvement of $7.33^{\circ}$ (range: $0.10-28.9^{\circ}$, $\mathrm{SD} 6.39^{\circ}$ ). Univariate analysis revealed that greater preoperative SL negatively impacted postoperative $\Delta \mathrm{SL}$ $\left(\mathrm{p}<0.01,95 \% \mathrm{CI}-0.40^{\circ}\right.$ to $-0.12^{\circ}$ ) (Table 3). Additionally, a greater anterior disk height correlated with a significantly decreased postoperative $\Delta \mathrm{SL}\left(\mathrm{p}=0.02,95 \% \mathrm{CI}-0.66^{\circ}\right.$ to $\left.-0.06^{\circ}\right)$. For each $1 \mathrm{~mm}$ increase in preoperative anterior disc height, there was a $2.8^{\circ}$ lowering in postoperative improvement in SL. A greater preoperative PI-LL mismatch was significantly associated with an increased postoperative $\Delta \mathrm{SL}$ ( $\mathrm{p}=0.03,95 \%$ CI $0.01^{\circ}$ to $0.19^{\circ}$ ). For each $10^{\circ}$ increase in preoperative PI-LL mismatch, there was a $1.0^{\circ}$ increase in postoperative SL. 


\section{Cureus}

\begin{tabular}{|c|c|c|c|c|c|}
\hline \multirow{2}{*}{ Effect } & \multirow{2}{*}{ B $\left(^{\circ}\right)$} & \multirow{2}{*}{ SE $\left({ }^{\circ}\right)$} & \multicolumn{2}{|c|}{$95 \% \mathrm{Cl}\left({ }^{\circ}\right)$} & \multirow{2}{*}{ p-value } \\
\hline & & & Lower & Upper & \\
\hline Level (2- vs 1-level) & -1.41 & 1.27 & -4.01 & 1.20 & 0.2785 \\
\hline Disk space & & & & & 0.8576 \\
\hline L3-L4* & 0.90 & 1.65 & -2.51 & 4.30 & 0.5915 \\
\hline L4-L5* & 0.28 & 1.27 & -2.39 & 2.85 & 0.8593 \\
\hline Age & 0.05 & 0.05 & -0.06 & 0.15 & 0.3859 \\
\hline BMI & 0.04 & 0.10 & -0.17 & 0.25 & 0.6888 \\
\hline Anterior disc height (mm) & -0.36 & 0.14 & -0.66 & -0.06 & 0.0197 \\
\hline Sex (male compared to female) & -0.01 & 1.25 & -2.57 & 2.55 & 0.9931 \\
\hline Prior surgery & -0.55 & 1.25 & -3.12 & 2.03 & 0.6663 \\
\hline Bridging osteophytes & 1.60 & 2.04 & -2.58 & 5.79 & 0.4383 \\
\hline Vacuum disk & 0.57 & 1.15 & -1.79 & 2.93 & 0.6244 \\
\hline Annular tears & -2.41 & 1.32 & -5.12 & 0.31 & 0.0797 \\
\hline Modic changes & 0.19 & 1.19 & -2.24 & 2.63 & 0.8716 \\
\hline Schmorl's nodes & 0.73 & 1.52 & -2.39 & 3.86 & 0.6341 \\
\hline Preop SL & -0.26 & 0.07 & -0.40 & -0.12 & 0.0009 \\
\hline $\mathrm{PI}$ & 0.07 & 0.04 & -0.02 & 0.16 & 0.1326 \\
\hline Preop LL & -0.04 & 0.06 & -0.15 & 0.07 & 0.4786 \\
\hline PI-LL & 0.10 & 0.05 & 0.01 & 0.19 & 0.0303 \\
\hline
\end{tabular}

\section{TABLE 3: Univariate mixed-effect linear regression coefficients for predictors of change in}

segmental lordosis.

*Note: comparison was made with the L5-S1 disk space.

$\mathrm{SE}=$ Standard Error; $\mathrm{Cl}=$ Confidence Interval $; \mathrm{BMI}=$ body mass index; Preop = preoperative $; \mathrm{SL}=$ segmental lordosis; $\mathrm{PI}=$ pelvic incidence; $\mathrm{LL}=$ lumbar lordosis

Using multi-predictor linear regression models of $\Delta \mathrm{SL}$, the presence of an annular tear was significantly associated with less $\Delta \mathrm{SL}\left(\mathrm{p}=0.02,95 \%\right.$ confidence interval $(\mathrm{CI})-5.34^{\circ}$ to $-0.38^{\circ}$ ) (Table 4). The presence of an annular tear decreased the $\Delta \mathrm{SL}$ by $3^{\circ}$. The $\Delta \mathrm{SL}$ in patients without an annular tear was statistically significant $\left(\mathrm{p}<0.05\right.$ ) for values of preoperative $\mathrm{SL}<34^{\circ}$ (Figure 1 ). $\Delta \mathrm{SL}$ in patients with an annular tear was statistically significant $(\mathrm{p}<0.05)$ for values of preoperative $\mathrm{SL}<23.9^{\circ}$ (Figure 2). Preoperative LL was not found to be associated with significant $\Delta \mathrm{SL}(\mathrm{p}=0.54)$. An equation for $\Delta \mathrm{SL}$ prediction based on significant factors is demonstrated below; see associated flowchart (Figure $3 A$ ). 


\section{Cureus}

\begin{tabular}{|c|c|c|c|c|c|}
\hline \multirow{2}{*}{ Effect } & \multirow{2}{*}{ B $\left(^{\circ}\right)$} & \multirow{2}{*}{ SE $\left({ }^{\circ}\right)$} & \multicolumn{2}{|c|}{$95 \% \mathrm{Cl}\left({ }^{\circ}\right)$} & \multirow{2}{*}{$p$-value } \\
\hline & & & Lower & Upper & \\
\hline Intercept & 7.19 & 2.64 & 1.96 & 12.41 & 0.0074 \\
\hline Preop SL & -0.32 & 0.08 & -0.48 & -0.17 & $<0.0001$ \\
\hline $\mathrm{PI}$ & 0.08 & 0.04 & -0.01 & 0.16 & 0.0721 \\
\hline Preop LL & 0.04 & 0.06 & -0.09 & 0.16 & 0.5452 \\
\hline Annular Tear & -2.86 & 1.25 & -5.34 & -0.38 & 0.0242 \\
\hline
\end{tabular}

TABLE 4: Multi-predictor linear regression model of change in segmental lordosis. Validated estimate of adjusted R-squared of 0.1449 .

$\mathrm{SE}=$ standard error $\mathbf{C l}=$ Confidence Interval; Preop = Preoperative $; \mathrm{PI}=$ Pelvic incidence $; \mathrm{LL}=$ lumbar lordosis

Range of Significant Change in Postop Segmental Lordosis $(P<0.05)$ Predicted by Preop Segmental Lordosis with No Annular Tear

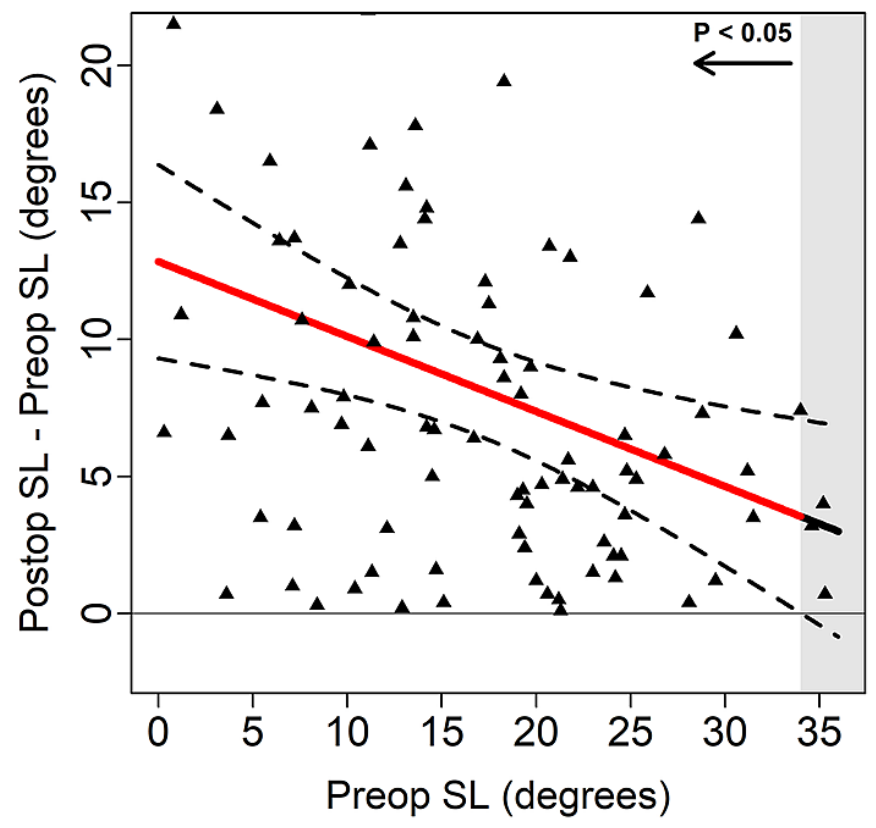

FIGURE 1: 95\% Scheffe confidence band which demonstrates that the change in segmental lordosis $(\mathrm{SL})$ is significant if the preoperative $\mathrm{SL}$ is $<34^{\circ}$ when no annular tear is found within that segmental level. A $4^{\circ}$ decrease in the preoperative $S L$ predicted a single degree greater change in the SL correction.

Postop $=$ Postoperative $;$ SL $=$ Segmental Lordosis $;$ Preop = Preoperative 


\section{Cureus}

Range of Significant Change in Postop Segmental Lordosis $(P<0.05)$ Predicted by Preop Segmental Lordosis with Annular Tear

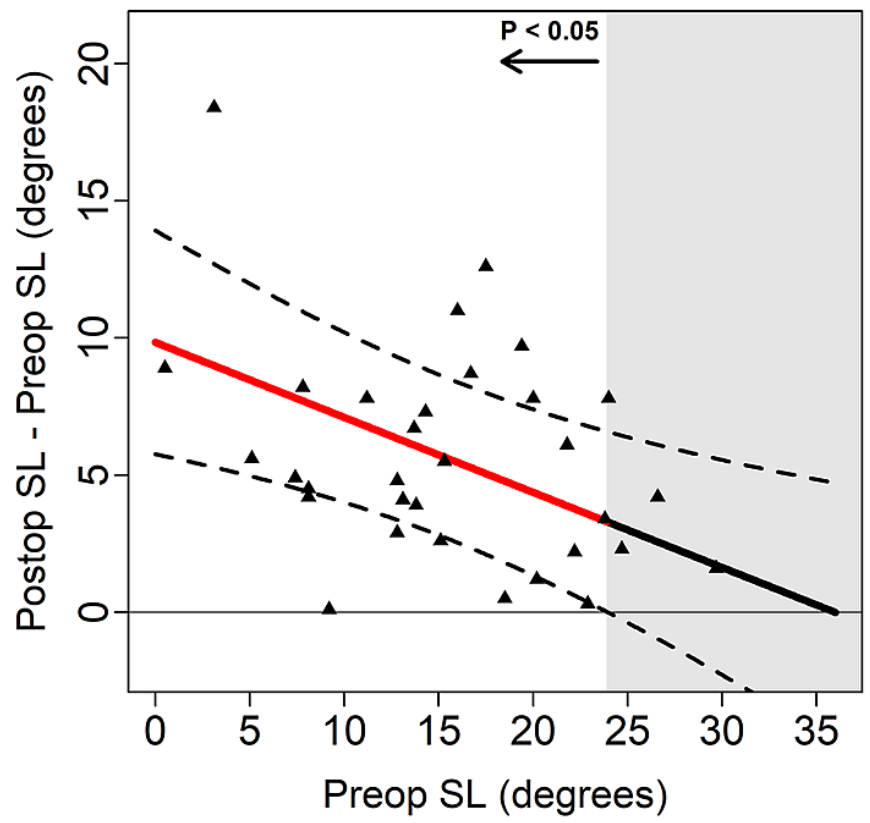

FIGURE 2: The above represents a $95 \%$ Scheffe confidence band which demonstrates that a change in segmental lordosis (SL) is significant if the preoperative $S L$ is $<23.9^{\circ}$ when an annular tear is found within that segmental level. A $4^{\circ}$ decrease in the preoperative SL predicted a single degree more SL correction. Additionally, an annular tear predicted $2.4^{\circ}$ less correction.

Postop $=$ Postoperative $;$ SL $=$ Segmental Lordosis $;$ Preop $=$ Preoperative 


\section{Cureus}

A Change in Segmental Lordosis

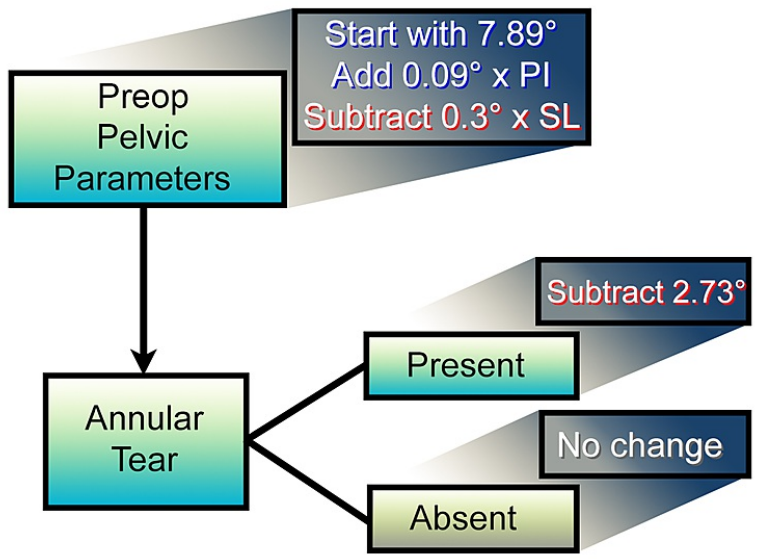

B Change in Lumbar Lordosis

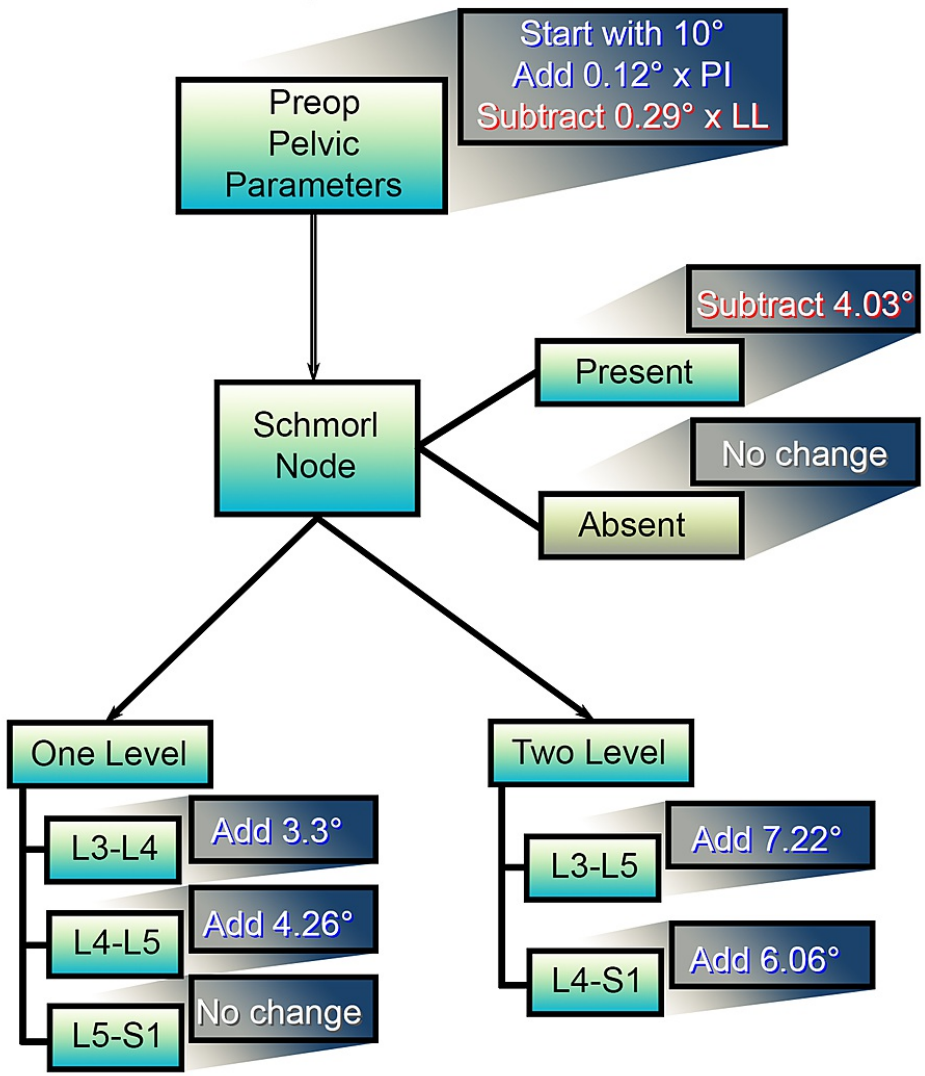

FIGURE 3: Flowchart for (A) predicting change in the segmental lordosis $(\Delta S L)$ where $(\Delta S L)=7.89^{\circ}-0.3\left[\right.$ Preop SL $^{\circ}+0.09$ [Preop PI $^{\circ}-2.73^{\circ} \mathrm{a}$ [note: subtract $2.73^{\circ}$ only if an annular tear is present] and (B) predicting change in the lumbar lordosis $(\Delta L L)$ after one- and two-level transforaminal lumbar interbody fusions (TLIFs) where $\Delta L L=10^{\circ}+0.12$

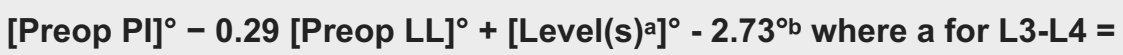
3.30, L4-L5 = 4.26, L3-L5 = 7.22, L4-S1 = 6.06 and for L5-S1 $=0$ and $b$ is subtracted only if a Schmorl's node is present. The blue highlight indicates added degrees and the red highlight indicates subtracted degrees. At most one addition should be made for each operative level; however, no change is made for operative level for one-level L5-S1 


\section{Cureus}

TLIFs. For example, a single level L4-5 TLIF with a preoperative SL of $7.8^{\circ}$, a preoperative LL of $43.7^{\circ}$, and a $\mathrm{PI}$ of $65.0^{\circ}$, when an annular tear is present but no Schmorl's node is present, the $\Delta S L$ is predicted to be $8.6^{\circ}\left[\right.$ i.e. $7.89^{\circ}+0.09\left(65^{\circ}\right)-0.3\left(7.8^{\circ}\right)-2.73^{\circ}=8.6^{\circ}$ ] and the $\Delta L L$ is predicted to be $9.4^{\circ}\left[\right.$ i.e. $10^{\circ}+0.12\left(65^{\circ}\right)-0.29\left(43.7^{\circ}\right)-0^{\circ}+4.26^{\circ}=9.4^{\circ}$ ]

$\Delta S L=7.89^{\circ}-0.3[\text { Preop } S L]^{\circ}+0.09[\text { PreopPI }]^{\circ}$

$-2.73^{\circ a}$

a: subtract only if annular tear present

$\Delta L L=10^{\circ}+0.12[\text { PreopPI }]^{\circ}-0.29[\text { Preop } L L]^{\circ}$

$+\left[\operatorname{Level}(s)^{a}\right]^{\circ}-2.73^{\mathrm{b}}$

$a: L 3-L 4=3.30, L 4-L 5=4.26, L 3-L 5=7.22$

$L 4-S 1=6.06, L 5-S 1=0$

b : subtract only if Schmorl's node present

$\mathrm{SL}=$ Segmental lordosis $; \mathrm{PI}=$ Pelvic incidence; $\mathrm{LL}=$ Lumbar lordosis

The SL cohort was further stratified into the 5 th percentile $\left(3.4^{\circ}\right)$, the mean $\left(16.6^{\circ}\right)$, and the 95 th percentile $\left(30.9^{\circ}\right)$. This analysis demonstrated that for a mean preoperative SL with an annular tear, a statistically significant $\Delta$ SL was only obtained if the preoperative LL was $>35^{\circ}$ and the PI was $>31^{\circ}$. With a preoperative SL in the 95th percentile, but without an annular tear, a statistically significant $\triangle$ SL was only obtained if the preoperative LL was $>50^{\circ}$ and the PI was $>60^{\circ}$. No significant change was observed for those with a preoperative SL in the 95th percentile with an annular tear. Otherwise, all other preoperative spinopelvic parameters were observed to cause significant post-operative SLs.

All TLIF levels demonstrated improved $\Delta \mathrm{LL}$, with a mean change of $5.50^{\circ}$ (range: $-14.8-39.2^{\circ}$, SD $7.16^{\circ}$ ). Univariate analysis revealed a $3.18^{\circ}$ increase in LL correction with two-level over one-level surgeries (Table 5). In both the univariate analysis and the multi-predictor linear regression model of $\Delta \mathrm{LL}$, greater preoperative LL negatively impacted $\Delta \mathrm{LL}$ (multi-predictor: $\mathrm{p}<0.01,95 \% \mathrm{CI}-0.43^{\circ}$ to $-0.15^{\circ}$ ) while increases in PI significantly increased $\Delta \mathrm{LL}$ (multi-predictor: $\mathrm{p}=0.03,95 \% \mathrm{CI} 0.01^{\circ}$ to $0.23^{\circ}$ ) (Table 6 ). A $3^{\circ}$ increase in preoperative LL predicted a single degree decrease in $\triangle \mathrm{LL}$, while an $8^{\circ}$ increase in PI predicted a single degree increase in $\triangle \mathrm{LL}$. The presence of a Schmorl's node predicted a $4.03^{\circ}$ decrease in $\triangle \mathrm{LL}$ ( $\mathrm{p}=0.03,95 \% \mathrm{CI}$ $-7.62^{\circ}$ to $\left.-0.43^{\circ}\right)$. A significant $\Delta$ LL was observed when PI was > preoperative LL as long as preoperative LL was $<57^{\circ}$ (Figure 4 ). An equation for $\Delta L L$ prediction based on significant factors is demonstrated below; see associated flowchart (Figure 3B). 


\section{Cureus}

\begin{tabular}{|c|c|c|c|c|c|}
\hline \multirow{2}{*}{ Effect } & \multirow{2}{*}{ B $\left(^{\circ}\right)$} & \multirow{2}{*}{ SE $\left({ }^{\circ}\right)$} & \multicolumn{2}{|c|}{$95 \% \mathrm{Cl}\left({ }^{\circ}\right)$} & \multirow{2}{*}{ p-value } \\
\hline & & & Lower & Upper & \\
\hline Level (2- vs 1-level) & 3.18 & 1.61 & -0.02 & 6.37 & 0.0515 \\
\hline Disk space * & & & & & 0.0894 \\
\hline L3-L4 & 5.42 & 2.47 & 0.51 & 10.34 & 0.0310 \\
\hline L4-L5 & 3.84 & 2.16 & -0.46 & 8.13 & 0.0793 \\
\hline L3-L5 & 8.05 & 3.19 & 1.71 & 14.39 & 0.0135 \\
\hline L3-L4 \& L5-S1 & 1.89 & 7.20 & -12.42 & 16.21 & 0.7933 \\
\hline L4-S1 & 6.24 & 2.41 & 1.45 & 11.03 & 0.0112 \\
\hline Age & 0.12 & 0.06 & -0.00 & 0.25 & 0.0593 \\
\hline BMI & 0.04 & 0.12 & -0.21 & 0.28 & 0.7722 \\
\hline Sex (male compared to female) & -0.55 & 1.49 & -3.52 & 2.41 & 0.7114 \\
\hline Prior surgery & 1.50 & 1.50 & -1.49 & 4.49 & 0.3214 \\
\hline Bridging osteophytes & 2.71 & 2.39 & -2.04 & 7.46 & 0.2601 \\
\hline Vacuum disks & -0.15 & 1.50 & -3.13 & 2.83 & 0.9205 \\
\hline Annular tears & 1.08 & 1.63 & -2.17 & 4.33 & 0.5101 \\
\hline Modic changes & -1.88 & 1.51 & -4.88 & 1.11 & 0.2150 \\
\hline Schmorl's nodes & -2.38 & 1.84 & -6.05 & 1.28 & 0.1998 \\
\hline PI & 0.01 & 0.05 & -0.10 & 0.12 & 0.8563 \\
\hline Preop LL & -0.23 & 0.06 & -0.36 & -0.11 & 0.0004 \\
\hline PI-LL & 0.16 & 0.05 & 0.06 & 0.26 & 0.0026 \\
\hline
\end{tabular}

TABLE 5: Univariate linear regression coefficients for predictors of change in lumbar lordosis.

*Note: comparison was made with the L5-S1 disk space.

$\mathrm{SE}=\mathrm{Standard}$ Error $\mathrm{CI}=$ Confidence Interval; $\mathrm{BMI}=$ Body mass index; Preop = Preoperative; $\mathrm{PI}=$ Pelvic incidence; $\mathrm{LL}=$ lumbar lordosis 


\section{Cureus}

\begin{tabular}{|c|c|c|c|c|c|}
\hline \multirow{2}{*}{ Effect } & \multirow{2}{*}{ B $\left(^{\circ}\right)$} & \multirow{2}{*}{ SE $\left({ }^{\circ}\right)$} & \multicolumn{2}{|c|}{$95 \% \mathrm{Cl}\left({ }^{\circ}\right)$} & \multirow{2}{*}{$p$-value } \\
\hline & & & Lower & Upper & \\
\hline Intercept & 9.99 & 3.79 & 2.45 & 17.52 & 0.0100 \\
\hline PI & 0.12 & 0.05 & -0.01 & 0.23 & 0.0290 \\
\hline Preop LL & -0.29 & 0.07 & -0.43 & -0.15 & $<0.0001$ \\
\hline Disk space * & & & & & 0.0904 \\
\hline L3-L4 & 3.30 & 2.30 & -1.27 & 7.88 & 0.1550 \\
\hline L4-L5 & 4.26 & 2.03 & 0.23 & 8.29 & 0.0388 \\
\hline L3-L5 & 7.22 & 2.99 & 1.28 & 13.17 & 0.0179 \\
\hline L3-L4 \& L5-S1 & 2.62 & 6.55 & -10.40 & 15.64 & 0.6898 \\
\hline L4-S1 & 6.06 & 2.20 & 1.68 & 10.43 & 0.0072 \\
\hline Schmorl's nodes & -4.03 & 1.81 & -7.63 & -0.43 & 0.0287 \\
\hline
\end{tabular}

TABLE 6: Multi-predictor linear regression model of change in lumbar lordosis. Validated estimate of adjusted R-squared of 0.1547.

*Note: comparison was made with the L5-S1 disk space.

SE = Standard Error $; \mathrm{CI}=$ Confidence Interval $; \mathrm{PI}=$ Pelvic incidence $;$ Preop = Preoperative LL = lumbar lordosis

Regions of Significant Increase in Postop Lumbar Lordosis $(P<0.05)$ Predicted by Preop PI and Preop LL

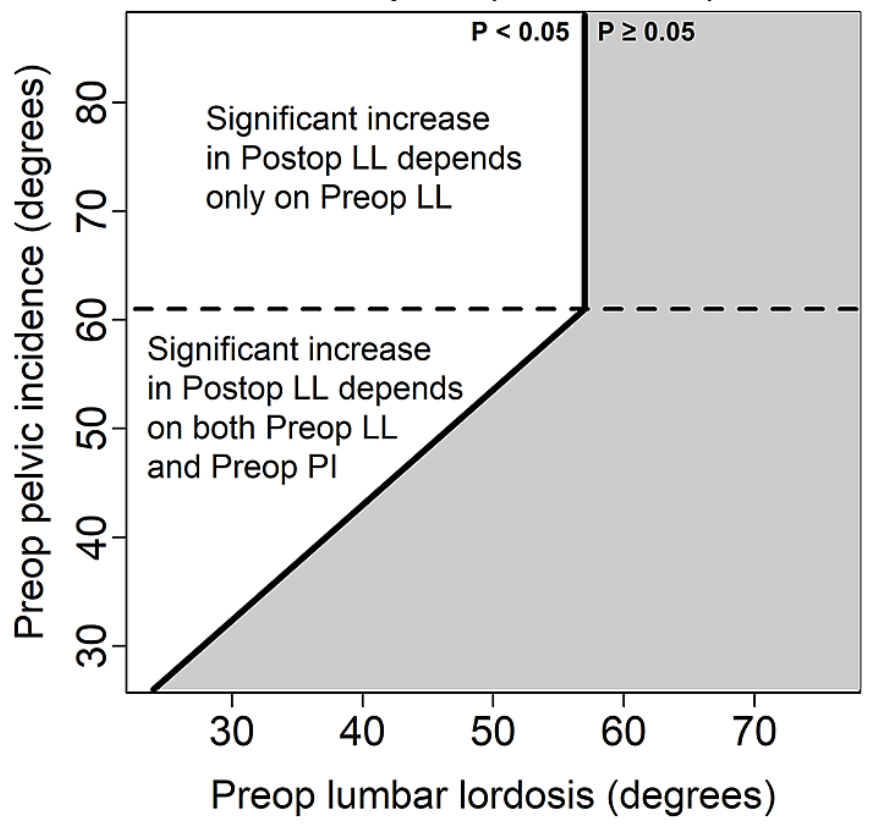

FIGURE 4: Representative plot demonstrating regions where preoperative lumbar lordosis (LL) and pelvic incidence (PI) predict significant correction in LL. A significant $\Delta$ LL was observed when $P I$ was greater than preoperative LL. A "ceiling" effect is observed at a LL of $57^{\circ}$ which matches the average $\mathrm{PI}$ of $57^{\circ}$. 


\section{Discussion}

All patients in our study had improvement of segmental lordosis only in the immediate postoperative period, with variation based on characteristics of the intervertebral segment and preoperative spinopelvic parameters. Of the intervertebral segment characteristics we studied, anterior disk height and the presence of an annular tear at least marginally impacted postoperative segmental lordosis change. Patients with a higher preoperative anterior disk height had significantly less $\Delta$ SL for a given instrumented level (i.e., there was a $2.8^{\circ}$ reduction with each additional $1 \mathrm{~mm}$ of anterior height). This suggests a decreased capacity for lordosis correction in these patients, which is a "ceiling" effect as these patients may already have maximal, well-preserved segmental lordosis. This effect, however, lost statistical significance when all predictors were considered, likely due to high variability. The presence of an annular tear was associated with a less postoperative change in SL $\left(2.9^{\circ}\right)$. This may be explained by the association of an annular tear with a more severely degenerated and less mobile disk. Alternatively, the small effect size of $<3$ degrees may not represent a true clinically relevant finding.

Lower preoperative SL and high preoperative spinopelvic mismatch are both associated in the literature with greater postoperative lordosis restoration $[18,19,24]$. Our study also found that a smaller preoperative SL and greater spinopelvic mismatch significantly increased postoperative $\Delta$ SL and $\Delta$ LL. Patients with a lower preoperative SL and LL, and a high mismatch logically have more capacity for restoration of lordosis, and this was demonstrated in our study. It also may suggest that improvement in SL and LL were a primary indication for surgery in these patients, which may have introduced selection bias. It also appears that lordosis restoration depends on both preoperative LL and PI when preoperative LL is < approximately $57^{\circ}$, which correspondingly was the average PI in this study population (i.e. when the LL is low enough to create a mismatch with the PI). When the preoperative LL is $>57^{\circ}$, postoperative LL appears to depend only on PI. This may suggest a "ceiling" effect in which an individual with an already optimized preoperative LL cannot achieve additional lordosis correction by undergoing a TLIF. This "ceiling” is dependent on the level of operation and disk characteristics; it decreases with more rostral levels and with the presence of Schmorl's nodes. While Schmorl's nodes had no effect on segmental lordosis, they predicted a $4^{\circ}$ decrease in achievable lordotic correction, which may be due to the more global degenerative disease/rigidity that they represent.

This study has several limitations including its retrospective design and inclusion of patients from a single surgeon and a standardized technique for open TLIF, which may impact the generalizability of the findings. Postoperative radiographic assessment was performed using immediate postoperative $\mathrm{x}$-rays, and not at longer-term follow-up. This study was designed to isolate the primary effect of the TLIF procedure on change in LL and SL. It is well understood that delayed subsidence may occur over time which may reduce LL and SL, but this is likely variably affected by individual patient factors (e.g. bone mineral density and BMI). Therefore, the study findings observed here likely represent the maximal extent of lordosis correction at the index surgical procedure and may demonstrate loss of effect in some patients over time. Additionally, our prediction equations require additional power in order to further reduce error.

\section{Conclusions}

The TLIF is a valuable procedure for restoration of lordosis, but individualized intervertebral segment and spinal alignment parameters may limit the degree of attainable correction. A greater anterior disk height and an annular tear are associated with a decreased $\Delta$ SL. Greater initial lordotic angles and lower spinopelvic mismatch lessen the potential for change in LL and SL due to a 'ceiling' effect of an otherwise well-aligned spine. Alternatively, patients with significant preoperative losses of segmental and overall lumbar lordosis may demonstrate potentially greater corrections of spinal alignment with TLIFs.

\section{Additional Information \\ Disclosures}

Human subjects: Consent was obtained or waived by all participants in this study. University of Florida IRB issued approval IRB202002814. Animal subjects: All authors have confirmed that this study did not involve animal subjects or tissue. Conflicts of interest: In compliance with the ICMJE uniform disclosure form, all authors declare the following: Payment/services info: All authors have declared that no financial support was received from any organization for the submitted work. Financial relationships: N/A declare(s) a grant from University of Florida. Research reported in this publication was supported by the University of Florida Clinical and Translational Science Institute, which is supported in part by the NIH National Center for Advancing Translational Sciences under award number UL1TR001427. The content is solely the responsibility of the authors and does not necessarily represent the official views of the National Institutes of Health. Other relationships: All authors have declared that there are no other relationships or activities that could appear to have influenced the submitted work.

\section{References}

1. Rosenberg WS, Mummaneni PV: Transforaminal lumbar interbody fusion: technique, complications, and early results. Neurosurgery. 2001, 48:569-74; discussion 574-5. 10.1097/00006123-200103000-00022

2. Liu J, Deng H, Long X, Chen X, Xu R, Liu Z: A comparative study of perioperative complications between 
transforaminal versus posterior lumbar interbody fusion in degenerative lumbar spondylolisthesis. Eur Spine J. 2016, 25:1575-80. 10.1007/s00586-015-4086-8

3. Potter BK, Freedman BA, Verwiebe EG, Hall JM, Polly DW Jr, Kuklo TR: Transforaminal lumbar interbody fusion: clinical and radiographic results and complications in 100 consecutive patients. J Spinal Disord Tech. 2005, 18:337-46. 10.1097/01.bsd.0000166642.69189.45

4. Mobbs RJ, Phan K, Malham G, Seex K, Rao PJ: Lumbar interbody fusion: techniques, indications and comparison of interbody fusion options including PLIF, TLIF, MI-TLIF, OLIF/ATP, LLIF and ALIF. J Spine Surg. 2015, 1:2-18. 10.3978/j.issn.2414-469X.2015.10.05

5. Gum JL, Reddy D, Glassman S: Transforaminal lumbar interbody fusion (TLIF). JBJS Essent Surg Tech. 2016, 6:e22. 10.2106/JBJS.ST.15.00003

6. Moskowitz A: Transforaminal lumbar interbody fusion. Orthop Clin North Am. 2002, 33:359-66. 10.1016/s0030-5898(01)00008-6

7. Fujimori T, Le H, Schairer WW, Berven SH, Qamirani E, Hu SS: Does transforaminal lumbar interbody fusion have advantages over posterolateral lumbar fusion for degenerative spondylolisthesis?. Global Spine J. 2015, 5:102-9. 10.1055/s-0034-1396432

8. Jagannathan J, Sansur CA, Oskouian RJ Jr, Fu KM, Shaffrey CI: Radiographic restoration of lumbar alignment after transforaminal lumbar interbody fusion. Neurosurgery. 2009, 64:955-63; discussion 963-4. 10.1227/01.NEU.0000343544.77456.46

9. Kepler CK, Rihn JA, Radcliff KE, et al.: Restoration of lordosis and disk height after single-level transforaminal lumbar interbody fusion. Orthop Surg. 2012, 4:15-20. 10.1111/j.1757-7861.2011.00165.X

10. Li FC, Chen QX, Chen WS, Xu K, Wu QH, Chen G: Posterolateral lumbar fusion versus transforaminal lumbar interbody fusion for the treatment of degenerative lumbar scoliosis. J Clin Neurosci. 2013, 20:1241-5. 10.1016/j.jocn.2012.10.031

11. Yijian Z, Hao L, Huilin Y, Bin P: Comparison of posterolateral fusion and posterior lumbar interbody fusion for treatment of degenerative spondylolisthesis: Analysis of spino-pelvic sagittal balance and postoperative chronic low back pain. Clin Neurol Neurosurg. 2018, 171:1-5. 10.1016/j.clineuro.2018.04.020

12. Sun J, Wang JJ, Zhang LW, Huang H, Fu NX: Sagittal alignment as predictor of adjacent segment disease after lumbar transforaminal interbody fusion. World Neurosurg. 2018, 110:e567-71. 10.1016/j.wneu.2017.11.049

13. Tian $\mathrm{H}, \mathrm{Wu} \mathrm{A}$, Guo M, et al.: Adequate restoration of disc height and segmental lordosis by lumbar interbody fusion decreases adjacent segment degeneration. World Neurosurg. 2018, 118:e856-64. 10.1016/j.wneu.2018.07.075

14. Glassman SD, Berven S, Bridwell K, Horton W, Dimar JR: Correlation of radiographic parameters and clinical symptoms in adult scoliosis. Spine (Phila Pa 1976). 2005, 30:682-8. 10.1097/01.brs.0000155425.04536.f7

15. Glassman SD, Bridwell K, Dimar JR, Horton W, Berven S, Schwab F: The impact of positive sagittal balance in adult spinal deformity. Spine (Phila Pa 1976). 2005, 30:2024-9. 10.1097/01.brs.0000179086.30449.96

16. Schwab F, Lafage V, Patel A, Farcy JP: Sagittal plane considerations and the pelvis in the adult patient . Spine (Phila Pa 1976). 2009, 34:1828-33. 10.1097/BRS.0b013e3181a13c08

17. Schwab F, Patel A, Ungar B, Farcy JP, Lafage V: Adult spinal deformity-postoperative standing imbalance: how much can you tolerate? An overview of key parameters in assessing alignment and planning corrective surgery. Spine (Phila Pa 1976). 2010, 35:2224-31. 10.1097/BRS.0b013e3181ee6bd4

18. Vaishnav AS, Saville P, McAnany S, et al.: Retrospective review of immediate restoration of lordosis in single-level minimally invasive transforaminal lumbar interbody fusion: a comparison of static and expandable interbody cages. Oper Neurosurg (Hagerstown). 2020, 18:518-23. 10.1093/ons/opz240

19. McMordie JH, Schmidt KP, Gard AP, Gillis CC: Clinical and short-term radiographic outcomes of minimally invasive transforaminal lumbar interbody fusion with expandable lordotic devices. Neurosurgery. 2020, 86:E147-55. 10.1093/neuros/nyz402

20. Eghbal K, Pourabbas B, Abdollahpour HR, Mousavi R: Clinical, functional, and radiologic outcome of singleand double-level transforaminal lumbar interbody fusion in patients with low-grade spondylolisthesis. Asian J Neurosurg. 2019, 14:181-7. 10.4103/ajns.AJNS_156_18

21. Carlson BB, Saville P, Dowdell J, et al.: Restoration of lumbar lordosis after minimally invasive transforaminal lumbar interbody fusion: a systematic review. Spine J. 2019, 19:951-8. 10.1016/j.spinee.2018.10.017

22. Tassemeier T, Haversath M, Jäger M: Transforaminal lumbar interbody fusion with expandable cages: Radiological and clinical results of banana-shaped and straight implants. J Craniovertebr Junction Spine. 2018, 9:196-201. 10.4103/jcvjs.JCVJS_56_18

23. Rothrock RJ, McNeill IT, Yaeger K, Oermann EK, Cho SK, Caridi JM: Lumbar lordosis correction with interbody fusion: systematic literature review and analysis. World Neurosurg. 2018, 118:21-31. 10.1016/j.wneu.2018.06.216

24. Galla F, Wähnert D, Liljenqvist U: Georg Schmorl Prize of the German Spine Society (DWG) 2017: correction of spino-pelvic alignment with relordosing mono- and bisegmental TLIF spondylodesis. Eur Spine J. 2018, 27:789-96. 10.1007/s00586-018-5503-6

25. Cheng X, Zhang F, Zhang K, et al.: Effect of single-level transforaminal lumbar interbody fusion on segmental and overall lumbar lordosis in patients with lumbar degenerative disease. World Neurosurg. 2018, 109:e244-51. 10.1016/j.wneu.2017.09.154

26. Sembrano JN, Yson SC, Horazdovsky RD, Santos ER, Polly DW Jr: Radiographic comparison of lateral lumbar interbody fusion versus traditional fusion approaches: analysis of sagittal contour change. Int J Spine Surg. 2015, 9:16. 10.14444/2016

27. Liang Y, Shi W, Jiang C, Chen Z, Liu F, Feng Z, Jiang X: Clinical outcomes and sagittal alignment of singlelevel unilateral instrumented transforaminal lumbar interbody fusion with a 4 to 5 -year follow-up. Eur Spine J. 2015, 24:2560-6. 10.1007/s00586-015-3933-y

28. Ould-Slimane M, Lenoir T, Dauzac C, Rillardon L, Hoffmann E, Guigui P, Ilharreborde B: Influence of transforaminal lumbar interbody fusion procedures on spinal and pelvic parameters of sagittal balance. Eur Spine J. 2012, 21:1200-6. 10.1007/s00586-011-2124-8 


\section{Cureus}

29. Kim SB, Jeon TS, Heo YM, Lee WS, Yi JW, Kim TK, Hwang CM: Radiographic results of single level transforaminal lumbar interbody fusion in degenerative lumbar spine disease: focusing on changes of segmental lordosis in fusion segment. Clin Orthop Surg. 2009, 1:207-13. 10.4055/cios.2009.1.4.207

30. Yen CP, Beckman JM, Vivas AC, Bach K, Uribe JS: Effects of intradiscal vacuum phenomenon on surgical outcome of lateral interbody fusion for degenerative lumbar disease. J Neurosurg Spine. 2017, 26:419-25 10.3171/2016.8.SPINE16421

31. Rice JW, Sedney CL, Daffner SD, Arner JW, Emery SE, France JC: Improvement of segmental lordosis in transforaminal lumbar interbody fusion: a comparison of two techniques. Global Spine J. 2016, 6:229-33. $10.1055 / \mathrm{s}-0035-1559583$

32. Yson SC, Santos ER, Sembrano JN, Polly DW Jr: Segmental lumbar sagittal correction after bilateral transforaminal lumbar interbody fusion. J Neurosurg Spine. 2012, 17:37-42. 10.3171/2012.4.SPINE111013

33. Lafage V, Schwab F, Vira S, Patel A, Ungar B, Farcy JP: Spino-pelvic parameters after surgery can be predicted: a preliminary formula and validation of standing alignment. Spine (Phila Pa 1976). 2011, 36:1037-45. 10.1097/BRS.0b013e3181eb9469

34. Harrell FE: Regression Modeling Strategies: With Applications to Linear Models, Logistic and Ordinal Regression, and Survival Analysis. Springer, Cham Heidelberg New York; 2015. 10.1007/978-3-319-19425-7

35. Brown H, Prescott R: Applied Mixed Models in Medicine. Wiley, Chichester, West Sussex Hoboken; 2015. 